\title{
Divorce: Causes and Effects on Children
}

\author{
Ubong E. Eyo \\ Department of Religion and Cultural Studies, \\ Faculty of Arts, University of Calabar, Nigeria \\ Email: ubongeyo [AT] yahoo.com
}

\begin{abstract}
This paper investigates "Divorce: Causes and Effects on Children." Worthy of note is that the fact that, divorce is not an uncommon experience in human history. It is experienced by couples irrespective of their social, religious, academic, political, economic, etc. status. One of the most hit in the saga of divorce are children born into the wedlock where divorce is experienced. The effects of this divorce on children are most often not well considered by the parents who embark on taking the status of divorcees. This becomes the onus of this paper using sociological and psychoanalytical approaches to the study of human institutions to study these effects on children, though not without looking at the causes of divorce. The paper reveals that the effects of divorce on children often are emotional, psychological, economical and religious spheres among others and recommends ways in which these effects can be minimized among children.
\end{abstract}

\section{INTRODUCTION}

Human society have units which are very peculiar to it. One of such is the institution called marriage. Every race and culture have her marriage custom and practice, some are closely similar while others are different, though the essence of this union tends to be similar in all cultures. This union which in the beginning often have an expectation of a life-long relationship sometimes have a contrary ending with its attendant effects on the human society. In some cases, there is a temporary separation while in some other cases the marriage ends in divorce. In the case of divorce, the effects are on the partners, the wider community and the children. This paper is an attempt to look into the causes of divorce and the effects on children. The paper is not focused on any particular tribe because the issue of divorce, its causes and effects on children is global and is not limited to a particular tribe or geographical sphere. In this paper, attention will be given to explain what marriage is as a precursor to divorce, the causes of divorce and the effects on children before pointing out some recommendation on what should be done to ameliorate some of these effects on children in particular, and the human society in general.

In this paper, we will not define the various terms/terminologies used differently, but will incorporate them into each of the sub-sections where they are treated. Reason for this is to let the thoughts of the paper flow seamlessly without a break. Hence, words like marriage, divorce, children, etc. will be defined within their context of study when they are treated in their sub-sections

\section{MARRIAGE}

Without marriage there is no divorce. It is one of the most important and basic societal institutions. Particularly in Africa when a person is up to a marriageable age but still remains single, it is seen as anomalous. According to Agwu N. Ukoma, "marriage is a mystical and physical union between a man and a woman and that marriage either in African context, biblical or the Greek concept is meant for the life long (sic) companionship between spouses" (2010:97). Ukoma's definition of marriage seems to be lopsided because marriage can be between more than two persons, hence the existence of polygamy and polyandry which are part of traditional African concept of marriage, apart from the fact that marriage does not necessarily need to be heterosexual in nature as the case may be, especially in the Western world.

The Encarta 2010 defines it as, "legal relationship between spouses: a legal recognized relationship, especially by a civil or religious ceremony, between two people who intend to live together as sexual and domestic partners" (Skolnick DVD). It further defines marriage as a, "specific marriage relationship: a married relationship between two people, or somebody's relationship with his or her spouse". On the other hand, J. S. Wright defines marriage as "the state in which men and women can live together in sexual relationship with the approval of their social group" (1993:742).

Marriage is commonly defined as a partnership between two members of opposite sex known as husband and wife. However, scholars who study human culture and society disagree on whether marriage can be universally defined. The usual roles and responsibilities of the husband and wife include living together, having sexual relations only with one another, sharing economic resources, and being recognized as the parents of their children. However, unconventional forms of marriage that do not include these elements do exist. For example, scholars have studied several cultural groups in Africa and India in which husbands and wives do not live together. Instead, each spouse remains in his or her original 
home, and the husband is a "visitor" with sexual rights. Committed relationships between homosexuals (individuals with a sexual orientation toward people of the same sex) also challenges conventional definitions of marriage.

Debates over the definition of marriage illustrate its dual nature as both a public institution and a private, personal relationship. On the one hand, marriage involves an emotional and sexual relationship between particular human beings. At the same time, marriage is an institution that transcends the particular individuals involved in it and unites two families. In some cultures, marriage connects two families in a complicated set of property exchanges involving land, labour, and other resources. The extended family and society also share an interest in any children the couple may have. Furthermore, the legal and religious definitions of marriage and the laws that surround it usually represent the symbolic expression of core cultural norms (informal behavioural guidelines) and values. It is on this note that, Ubong E. Eyo points out that, "marriage is a complex affair with social, emotional and religious (though sometimes with economic and political) undertones which often overlap so firmly that each undertone cannot be separated from each other" (2017:46).

Marriage is the beginning of a new family. Frank Cox observes that family "is the basic unit of [family] organization and if defined functionally, family is essentially universal" (1981:35). Among Africans in particular, marriage is not only for the living, it a union where the living, the dead and the yet unborn meet. Hence John Mbiti says that, "It is the point where all members of the community meet; the departed, the living and those yet unborn" (1973:133). Marriage is therefore a duty, a requirement from the corporate society, and a rhythm of life in which everyone must participate. To Africans in particular, the essence of marriage is procreation. Hence the Efik people have an old adage which says, 'oto mkpon oyom mbo, odo anwan oyom eyen', which means, 'a person who plants cocoyam is looking for tuber, a man who marries a wife is looking for a child'. Wife primarily is meant for procreation and companionship, marriage and procreation are a unity among Africans. Without procreation, marriage is incomplete, because this is a unity which attempts to recapture at least in part the lost gift of immortality in the African concept of immortality. It is a religious obligation by means of which an individual contributes to the seeds of life towards human struggle against the loss of original immortality. It is axiomatic that "husband and wife are reproduced in their children, thus perpetuating the chain of humanity" (Eyo 2017:49). Eyo further points out that, "Africans believe that if one dies without an offspring, he/she will not be remembered". This is in line with Mbiti's question, "if you don't get married and have children, who will pour out libation to you when you die?" (1969:134). Children are therefore very important components of marriage.

\section{DIVORCE}

Meaning and Understanding of Divorce: Edet Ukpong has defined divorce as, "a legal dissolution of the marriage relation; any formal separation of a man and his wife according to established custom; a complete separation of any kind" (2014:185). The word originally referred to the dissolution of legal marriage, though it is now also being used for the separation of two institutions or situations, one from the other, e.g. the separation of the state from the church or other religious bodies. Worthy of note is the fact that, there is no divorce except there was a legal bond of marriage. Hence, when people who co-habited decide to separate, one cannot speak of them as being divorced because they were not officially married. Divorce is a "recognized datum of modern life, though it is not always socially approved" (Allan Fromme 1969:131). It is anti-social and unlike marriage is not often celebrated - no fanfare, eating, dancing, etc. It is often gloomy and very traumatic because of the reason(s) and the concomitants of divorce. Divorce is never a day's journey, it takes time and in some cases it is very cumbersome. The reason for divorce process being cumbersome is to give the couple time for proper thinking and a re-think about their decision to divorce.

Causes of Divorce: It is axiomatic that, there is no smoke without fire. The same is applicable to divorce. Religionists, economists, anthropologists, medical scientists, sociologists, etc. have all proffered one reason or the other as cause(s) for divorce. In this segment of this presentation, we will attempt looking at some of these causes from a broader perspective.

Religious Reasons: Religion is expected to give stability to the society but sometimes, the contrary is the reality. Religion sometimes can cause divorce. In the case of Chief Engr. Duke Effiom and Mrs. Dorathy Effiom, when the wife decided to change from the husband's church to Brotherhood of the Cross and Star, this led to divorce ( (Eyo 2017:49). Writing on Social Problems and Religion, Etim E. Okon points out that "religion which ought to be a pillar of the society sometimes becomes caterpillar wherewith the society is destroyed" (Okon 2011:230). This can be seen in the role religion plays in the issue of divorce. A change of denomination or religion by a partner may cause instability in the family which may result in divorce. In this way, one of the causes of divorce can be religion.

Apart from the above case, sometime prophets may prophesy to a partner that the ill-fortune befalling him/her is because of the spouse or a member of the spouse's family, and that the best bet out of the predicament is divorce. Religion in this way also can spark up divorce. In the Christian circle, scriptural text like, "Therefore come out from them and be separate, says the Lord. Touch no unclean thing, and I will receive you" (2 Cor. 6:17 NIV) is often quoted to support such prophecies. 
Economic Reasons: This seems to be one of the major causes of divorces. "The American Journal of Sociology recently published a study which found out that a husband's unemployment can be a key factor behind divorce" (Top Reasons for Divorce, 2014). In fact, lack of money can often cause marital problems to flare into a divorce filing. A married couple facing financial difficulties is often under a lot of stress, which in turn can lead to constant arguing and lack of communications. Couples who don't see eye to eye on spending habits or couples where one spouse has and controls the finances of the home can face marital strain that can culminates in divorce. Wasteful management of economic resources by a spouse (mostly wives, though some husbands may be also involved) may lead to the other spouse seeking divorce.

Age at First Marriage: Writing on Sociology of the Family, Ebingha E. Enang rightly points out that, another factor that can cause divorce in marriage is,

The age at first marriage. Those who marry for the first time in their teens are prone to divorce because the partners are usually less matured - intellectually, emotionally, and experientially - in their teenage years than when older, and thus are probably less likely to make sound marital choices (2003:56).

It has been suggested that because marriage partners are too young to make important decision on whom to marry, this often lead to divorce. In Africa particularly, teenage marriage is common among the lower class, especially the illiterate (apart from those in Islamic faith) and "so is the divorce rate due to financial pressure, lower job status, low educational level and more pre-marital pregnancy” (quoted in Enang, 2003).

Domestic violence: Domestic and gender violence accounts for some of the divorce cases. In cases where "violence is meted out on the woman in marriage by either the spouse or in-laws, it may lead to divorce, especially in this age of gender equality and equity" (Eyo 2016:131). The violence can be physical, sexual, verbal, economic, emotional, etc. violence.

Sexual incompatibility: Edet A. Ukpong opines that, "incompatibility in sexual matters or unwillingness of a spouse to perform the sexual act for a long period of time" (2014:190) may lead to the other spouse filing for and obtaining divorce. Such is often referred to in the court as 'denial of conjugal rights'.

Extramarital Sexual Affairs: This is mainly on the part of the wife. Africa which is polygamous in nature do not often frown at husbands having extramarital sexual affairs, but when it involves a wife, it is always treated with disdain and can lead to divorce.

Medical Reasons: Health matters such as impotency with a resultant childlessness, on either the wife or husband, protracted illness, insanity, HIV/AIDS, etc. may lead to divorce. Infertility in particular, coupled with societal pressure can lead to divorce.

Addiction: People can become addicted to substances, behaviours or even other people. Whether it's drugs, gambling, or alcohol, addiction can wreck a person's life. As a person's addiction gains more control, they often find themselves in peril of losing employment, friends, and their marriage. "Addicts often exhibit behaviour that is unacceptable in a marriage, i.e. lying, stealing, and betrayal of marital trust, and consequently addiction makes the list of top reasons why couples divorce, according to Henry Gornbein, a family law specialist” (Top Reasons for Divorce 2014:E-copy).

Change in Status: In a study of Behavioural Pattern of People and Social Problem, it can be noticed that a change of status sometimes affect the life-style of some people. "A little uplifting may bring new friends, social status and consequently new way of life" (R. E. Roy 2006:214). In some cases a spouse who fails to meet up the new standard of life may be divorced to enable the person marry a new spouse to fit into the new status. The same may also be applicable when a person drops in societal status. He/her spouse may desire divorce because of shame.

Unrealised Expectations: Prior to marriage, may be during courtship or before then, a spouse may have had certain expectation(s). People come to marriage with different expectations - people sometimes want spouses who will meet their economic, social, religious, academic, etc. needs. When such expectations are not met, the marriage bond may suffer divorce.

Generally, reasons for divorce are varied, some of them may be very insignificant while others may not. What may be significant to a couple seeking divorce may be insignificant to another couple. Whatever the case may be, divorce is not pleasant at its end point, this is because of its attendant consequences it has on the society. 


\section{DIVORCE AND CHILDREN}

Divorce affects all strata of family and society, because marriage is a social contract. Therefore anything that affects marital bond must advertently or inadvertently affect the society. Since the focus of this paper is on effects of divorce on children, we will limit our work to it. This brings us to the definition of who a child is.

Definition and Understanding who a Child is: Encyclopædia Britannica defines a child as "a young person especially between infancy and youth, a son or daughter of human parents, an unborn or recently born person" (2014:E-Copy). This definition ties a child to human parents and even speaks of a child as one that may be an infant but does not exceed youthful age, as well as one who may still have been in the womb as an unborn person. Another lucid definition of a child is that given as a "young human being: a young human being between birth and puberty, somebody not yet of age: somebody under a legally specified age who is considered not to be legally responsible for his or her actions, immature adult: an adult who is regarded as behaving in a childish or inappropriately childlike way, etc." (Child 2009:E-copy). Other definitions of a child as a product of something, descendant of a person, etc. are not really our main focus in this paper. Defining who a child is brings to the fore that in some parlance, a child is defined as a person who is under the age of fourteen years.

However, for the purpose of our present discussion it is safe to adopt the definition of the word 'child' contained in two international Instruments namely:

The United Nations Convention on the Rights of the Child 1989 and the O.A.U. Charter on the Rights and Welfare of the Child 1991 both of which Nigeria is a signatory. Under Article II of the latter, a child means every human being below the age of 18 years. Also under Article I of the U.N. Convention a child is every human being below the age of 18 years unless, under the law applicable to the child, maturity is attained earlier (Child's Right Act 2016:E-copy).

Before the law and the society, a child is immature in thought and action and vulnerable. This makes a child dependent on the first instance on its parents and secondly on other adults in the society. The vulnerability of a child gives the child some rights, e.g. right to life, education, welfare, proper upbringing, care by parents, etc. The proper setting and locus for these rights is the family where marriage is the bond. So if there is a divorce between the parents, the child/children suffer the most. Below are some of the effects of divorce on children

Effects of Divorce on Children: The following are some of the effects of divorce on children:

Problems of Adjustment: The children will confront questions from their peers, particularly when they are in primary or nursery school, about why they have only one parent at home. They will have to adjust to a change in primary relationships, and possibly to restricted interaction with one of the parents (mostly the father). Apart from this, "they have to cope with parental conflict, which may continue after the divorce, and with attempts by each parent to gain the child's loyalty and affection at the expense of the other parent" (Lauer 1995:251). It is not surprising then, that children whose parents are divorced are prone to both emotional and physical problems. Those whose parents divorced when they were young adults tend to find the experience painful and disillusioning, and they have a difficult time adjusting to the dissolution of the marriage bond between their parents

Psychological Problems: Divorce tends to affect the children of divorced parents psychologically. Sometimes the children feel withdrawn when they are with their peers, especially when their peers are discussing about their own parents and family life. They may even carry this psychological problem into their own marriages.

Object of Abuse by Parents/Others: Sometimes, divorced parents vent their anger on their children in the absence of their divorced spouse. They transfer aggression to their children. This often than not affects the children's self-esteem who are may also become objects of abuse and ridicule by the larger society. Therefore instead of having parental warmth which is expected of a growing child, these children end up having abuses.

Hatred Towards One Parent: Sometimes children from divorced marriages tend to develop hatred towards one of the parents whom they feel was the cause of the divorce. This is usually based on the information they received, especially when the divorce happened when they were very young.

Lack of Balance Training: Children are normally expected to be trained by both parents - each supplying what may be deficient in the life of the other parent. In the case of divorce, the children will only be trained by one parent. Single parenthood have its own flaws which are easily transferred to the children.

Prone to Social Problems: Lauer rightly points out that, "children from divorced marriages are prone to social problems" (1995:442). With the deficiency in their upbringing, they may decide to join peers and adults outside who may 
introduce them to vices which are inimical to their lives and that of the society. They may indulge in sexual vices, illicit drugs, alcoholism, robbery, etc. Even though children from unbroken homes may also be involved in these vices, Lauer maintains that the rate is more among children from divorced homes (444). Children from divorced homes may use the visit of one parent as an avenue of going out to perpetuate evil. This may increase their propensity to social problems.

Economically: Though economically, children from both non-divorced and divorced homes may suffer economically, but studies show that children from divorced homes suffer more economically. This affects their educational and other endeavours in life

Starting of Live All Over Again: Worthy of note is the fact that, divorce may have positive effect on children, especially in a bad marriage. In unions where parents bicker, quarrel and fight at the lest provocation even to the point of attracting neighbours, being naked in the public and before their children, a breakdown of such marriage may be helpful to enable the children start their lives all over again. It has rightly been pointed out that, "divorce can have a positive outcome by freeing individuals from painful and difficult marriages" (Olson \& Defrain, 1994:96). A high-conflict home can have negative effects on all members of the family (children inclusive). Children may respond to this type of environment with depressing anger, troubles in school, etc. In such cases, the dissolution of the marriage may have positive effect on the children. It is on this note that Edet A. Ukpong avers that, "the children may suffer initial psychological, financial and otherwise effects, their separation from one of their parents may cause them initial emotional upset or trauma, but they have the advantage of being from conflict and hostility" (2014:195).

Summary: Marriage is supposed to be a union of bliss with its attendant positive effects, especially on children, but in some cases marriage bond has been broken due to divorce. Causes of divorce ranges from religious, economic, change of social status to health challenges among other things. When there is a marriage breakdown resulting in divorce, all strata of the society normally have their share of what may seem to be positive effects, though the negative effects are often more. One of the worst hit in the saga of divorce are children who may suffer physically, psychologically, economically and otherwise. They may become objects of abuse, hatred towards one of the parents (if not both), unbalance unbringing and training among other negative effects, even though it may have a positive effect of freeing the children from hostile and quarrelsome environment, causing them to start a new life with seeming better prospects. The negative effects of divorce on children far outweighs the positive effects.

Conclusion: Divorce, though may have some positive effects specially on the divorcees in particular and other members of human society (especially members of the family) in general, its negative effects on children out numbers the positive effects. The society can be better if divorce can be eradicated or reduced to bearest minimum. It is on this note that this paper makes the underlisted recommendations as a way of dealing with the effects of divorce on children.

\section{RECOMMENDATIONS}

1. Eradication of Divorce: The first recommendation on stopping negative effects of divorce on children is to eradicate divorce in its totality. Parents should learn to stay within the ambit of their marriage bond peacefully and nurture their children within it accordingly.

2. Adequate Provision to carter for children's welfare: Where eradication of divorce is not possible, parents should make adequate plans to take care of the psychological, emotional and economic needs of their children. Plans for the education of the children should be adequately made to avoid the children from becoming dropouts in school. This should also include plans for other financial needs of the children.

3. Affirmation of Parental Love: Parents (whether as single parent or not) should constantly affirm their love to their children. It may mean, the children spending quality time with both parents (though both are residing separately).

4. Proper Education on the need for successful marital life: Children from broken homes should be given proper education as to the need of having a proper and successful marriage devoid of divorce. This will help them not to see divorce as an option but an abnormally to be avoided. 


\section{REFERENCES}

- African Charter of the Rights and Welfare of the Child 1991. (March, 1991). African Journal of International and Comparative Law, March 1991, E-Copy.

- Child. (2009). In M. Encarta, Microsoft Encarta (pp. E-Copy). Microsoft Corporation.

- Child. (2014). In E. Britannica, Encyclopaedia Britannica Ultimate Reference Suite (pp. E-Copy). Chicago: Encyclopædia Britannica.

- Child's Right Act. (2016, January 26). Retrieved from Nigerian Law Guru: www.nigerianlawguru.com/.../human\%20rights\%20law/THE\%20LEGAL\%20RIGHT...

- Cox, F. D. (1981). Human Intimacy: Marriage, the Family and its Meaning. New York: West Publishers.

- Enang, E. E. (2003). Sociology of the Family. Calabar: Tabson Global Resources.

- Eyo, U. E. (2016). Jesus and Women in Johannine Gospel: A Paradigm Shift in an Androcentric Culture and the Implications for the Efik People. Calabar: Unpublished Ph.D. Thesis submitted to the Department of Religious and Cultural Studies, University of Calabar.

- _ _ _ (2017). A Gender Perspective of the Efik Marriage Rites. (S. D. Shishima, \& S. F. Kehinde, Eds.) Journal of the Nigerian Association for the Study of Religions, Vol. 26 No. 1 January, 2017, 45-52.

- Fromme, Allan. (1969). Sex and Marriage. New York: Barnes and Noble Inc.

- Lauer, R. H. (1995). Social Problems and the Quality of Life. Dubuque (Iowa): Wm. C. Brown Communications, Inc.

- Mbiti, J. S. (1973). Love and Marriage in Africa. London: Longman Group.

- Okon, E. E. (2011). The Sociological Imagination of Religion. In O. E. Etim (Ed.), Readings in the Scientific Study of Religion (pp. 224-246). Calabar: University of Calabar Press.

- Olson, D. H., \& Defrain, J. (1994). Marriages and Families: Intimacy, Diversity and Strengths. New York: McGraw Hill.

- Roy, R. E. (2006). Behavioural Pattern and Social Problems. New York: Reformed and Presbyterian Publishing.

- Skolnick, A. (2009). Marriage. In W. A. Redmond, Microsft Encarta (p. DVD). Microsoft Corporation.

- Top Reasons for Divorce. (2014, June 26). Retrieved from Love To Know: http://divorce.lovetoknow.com/Top_Reasons_for_Divorce

- Ukoma, A. N. (June, 2010). Wideowhood in a Matrilineal Society: A Case Study of the Igbo of South Eastern Nigeria. African Journal of Religion, Culture and Society, Vol. 2 No, 2, 96-102.

- Ukpong, E. A. (2014). Marriage and the Family among the Akwa Ibom People: Anthropological Perspectives. Uyo: Impact Impression Enterprise.

- Wright, J. S. (1993). Marriage. In J. D. Douglas et.al. (Ed.), New Bible Dictionary (pp. 742-746). Leicester: IVP. 